\title{
AVALIAÇÃO DA SUSTENTABILIDADE EM AGROECOSSISTEMAS: FORMAÇÃO CONCEITUAL E APLICAÇÃO A UMA REALIDADE REGIONAL
}

\author{
João Carlos Costa Gomes ${ }^{1}$ \\ Luiz Augusto Ferreira Verona ${ }^{2}$ \\ José Ernani Schwengber ${ }^{3}$ \\ Gustavo Crizel Gomes ${ }^{4}$
}

\begin{abstract}
RESUMO
É relatada uma experiência de construção do conhecimento na avaliação de sustentabilidade de agroecossistemas no território sul do Rio Grande do Sul com a utilização do marco teórico MESMIS - Marco para a Avaliação de Sistemas de Manejo de Recursos Naturais Incorporando Indicadores de Sustentabilidade por meio da aplicação do marco teórico à realidade local. Foi realizado um curso teóricoprático para um grupo multidisciplinar com a aplicação empírica da proposta metodológica de forma participativa com quatro famílias em quatro agroecossistemas. Alguns pontos comuns foram identificados nos agroecossistemas estudados: três apresentam problemas relacionados à água, tema fundamental e transversal às múltiplas dimensões da sustentabilidade, afetando qualidade de vida, saúde, ambiente e viabilidade do agroecossistema. A dependência a insumos externos, principalmente para sistemas de produção de base ecológica e a sucessão na agricultura familiar emergiram como pontos críticos para a sustentabilidade da agricultura familiar na região.
\end{abstract}

Palavras-chave: capital social, indicadores, manejo, redes locais, sistemas de produção.

\section{SUSTAINABILITY ASSESSMENT IN AGROECOSYSTEMS: CONCEPTUAL TRAINING AND APPLICATION TO A REGIONAL REALITY}

\begin{abstract}
It is reported a building experiment on the evaluation of knowledge of agroecosystems' sustainability in Southern region of Rio Grande do Sul, using the theoretical framework 'MESMIS' - Frame for the Evaluation of Management Systems

1 Graduado em Agronomia (UFPel). Mestre em Extensão Rural (UFSM). Doutor em Agroecologia e Desenvolvimento Sustentável (U. Córdoba). Pesquisador da Embrapa. Pelotas, RS. E-mail: costa.gomes@Embrapa.br

${ }^{2}$ Graduado, Mestre e Doutor em Agronomia (UFPel). Pós-doutor (UTFPR). E-mail: verona.luiz@gmail.com

${ }^{3}$ Graduado, Mestre e Doutor em Agronomia (UFPel). Pesquisador da Embrapa. Pelotas, RS. E-mail: jose.ernani@Embrapa.br

${ }_{4}$ Graduado e Mestre em Agronomia (UFPel). Doutor em Sistemas de Produção Agrícola Familiar (SPAF/UFPel). Bolsista de Pós-doutorado do SPAF/UFPel/Embrapa Clima Temperado. E-mail: crizelgomes@gmail.com
\end{abstract}


for Natural Resources, incorporating sustainability indicators through the application of the theoretical frame to the local reality. It was developed a practical-theoretical course for a multidisciplinary group with an empirical application of the methodological proposal as a participatory way with four families in four different agro-ecosystems. Some common points were identified in the studied agroecosystems: three of them showed problems related to the water, fundamental and transversal theme of the multiple dimensions of sustainability, affecting life quality, health, environment and viability of the agroecosystem. The dependency on external inputs, mainly for ecological based production systems and for succession on the families exploring agriculture, also emerged as critical points to the regional family farming.

Keywords: indicators, management, networks, production systems, social capital.

\section{INTRODUÇÃO}

Este texto relata uma experiência empírica de construção do conhecimento na avaliação da sustentabilidade em agroecossistemas no território sul do Rio Grande do Sul. O objetivo foi fundamentar alguns conceitos e verificar a possibilidade de que uma ferramenta de avaliação de sustentabilidade possa colaborar no entendimento de agroecossistemas familiares e contribuir para uma agricultura mais sustentável, seja por mudanças na gestão das propriedades ou no manejo dos sistemas de produção. A realização do trabalho, que incluiu a construção de indicadores com os agricultores, faz parte de uma rede de pesquisa participativa com representantes da Embrapa Clima Temperado, do Programa de Pós-graduação em Sistemas de Produção Agrícola Familiar da UFPel (SPAF/UFPel), da Emater/RS, do Centro de Apoio e Promoção da Agroecologia CAPA e de organizações da Agricultura Familiar da região (REICHERT; GOMES, 2006; VERONA, 2008; PERERA; GOMES, 2009; ALVES; REICHERT, 2014).

O curso foi realizado na Estação Experimental Cascata, da Embrapa Clima Temperado, em Pelotas/RS, local dedicado exclusivamente à construção da base científica da Agroecologia e fez parte do processo de qualificação metodológica do grupo para contribuir com a consolidação da agricultura familiar de base ecológica no território sul do Rio Grande do Sul (GOMES et al., 2006). Desde meados dos anos 90 a Estação Experimental Cascata sedia o Fórum da Agricultura Familiar, espaço de concertação sociopolítica e de controle social sobre Políticas Públicas (RECH, 2015; ALVES et al., 2016). O Fórum representa uma rede sociotécnica (CHARÃO-MARQUES, 2009) que articula o capital social ${ }^{5}$ (DUQUE, 2013; SANTOS, CARNIELLO; MURADE, 2013), baseado em confiança e cooperação como "sociabilidade construída" (RIBEIRO; CALLOU, 2015) no cotidiano dos atores que dela fazem parte e representa poderoso instrumento na busca de um desenvolvimento mais sustentável.

Foi realizado um curso teórico sobre o Método MESMIS - Marco para a Avaliação de Sistemas de Manejo de Recursos Naturais Incorporando Indicadores de Sustentabilidade com a aplicação do conhecimento oferecido por essa base em

\footnotetext{
${ }^{5}$ O conceito "capital social" foi desenvolvido por Lyda J. Hanifan em 1916 referindo-se a coisas intangíveis relevantes para a vida cotidiana das pessoas, como "boa vontade, amizade, solidariedade, interação social entre os indivíduos e as famílias que compõem uma unidade social". Segundo o autor, a interação entre vizinhos gera acúmulo de capital social, que pode satisfazer necessidades sociais do grupo com potencial para a melhoria das condições de vida de toda a comunidade, que como um todo se beneficiará pela cooperação das partes (HANIFAN, 1916).
} 
quatro agroecossistemas, representados por unidades familiares da região. O Método MESMIS indica como atributos equidade, autogestão, produtividade, estabilidade, resiliência, confiabilidade, adaptabilidade, como explicitado na Figura 01 e tem sido aplicado em estudos sobre desenvolvimento sustentável (MASERA; LÓPEZ-RIDAURA, 2000; ASTIER et al., 2003; SOUZA; MARTINS; VERONA, 2017).

Figura 1 - Esquema geral do método MESMIS: relação atributos, dimensões e indicadores de sustentabilidade

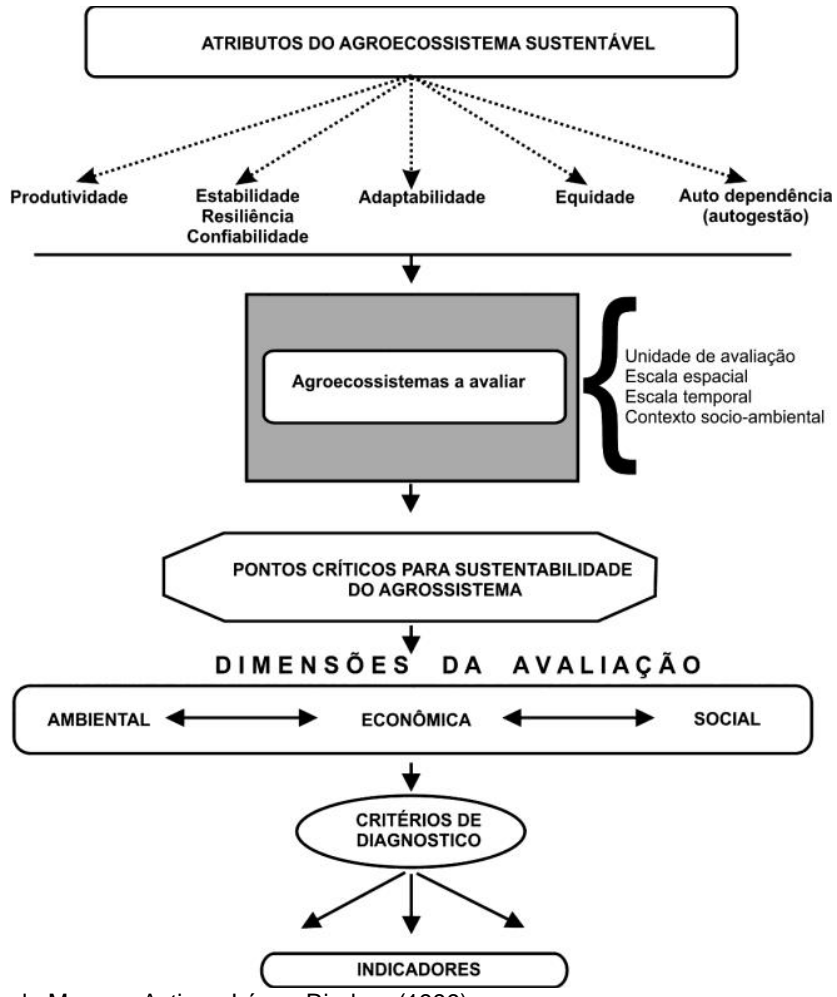

Fonte: Adaptado de Masera, Astier e López-Riadura (1999).

O conceito "desenvolvimento" pode ser usado desde diferentes abordagens teóricas que variam em complexidade e escopo e onde é recorrente a preocupação sobre o papel do Estado (SOPEÑA, 2015). No ambiente deste estudo o Estado tem contribuído com importantes Políticas Públicas de Pesquisa, Assistência Técnica e Ensino no tema agroecologia, que segundo a clássica definição de Sevilla Guzmán e González de Molina (1993), "além de simplesmente tratar sobre o manejo ecologicamente responsável dos recursos naturais, constitui-se em um campo do conhecimento científico que, partindo de um enfoque holístico e de uma abordagem sistêmica, pretende contribuir para que as sociedades possam redirecionar o curso alterado da coevolução social e ecológica, nas suas múltiplas inter-relações e mútua influência". O enfoque agroecológico contempla muitos elementos fundamentais. Um é o foco no território, o que privilegia a participação da sociedade civil na priorização das demandas e na alocação dos recursos públicos, conferindo protagonismo aos 
atores locais (FIALHO; WAQUIL, 2008; FREITAS; FREITAS, 2016). O processo participativo, por sua vez, permite mobilizar o potencial endógeno, essencial para o entendimento dos fatores que constituem as bases para qualquer estratégia de desenvolvimento rural que busque patamares crescentes de sustentabilidade (CAPORAL; COSTABEBER; PAULUS, 2011). Neste sentido, a valorização do local, da participação e da endogeneidade são chave para um estilo de intervenção que atenda preceitos de justiça social, com ações dirigidas a segmentos até então pouco visíveis e atendidos pelas políticas públicas (NICOLA; CHARÃO-MARQUES, 2016).

Durante a parte teórica foram trabalhados conceitos relevantes para o processo de formação, um dos objetivos do curso, bem como para sua aplicação em realidades concretas com a valorização da participação e dos conhecimentos dos agricultores familiares da região. Foram abordados temas como o entendimento comum do conceito sustentabilidade; a construção de indicadores de sustentabilidade para diferentes agroecossistemas, com integração e apresentação de resultados; a caracterização de sistemas de produção; o desenvolvimento de habilidades em trabalhos com foco sistêmico, abordando de forma participativa as dimensões epistemológica, metodológica, sociológica e tecnológica da sustentabilidade (GOMES; MEDEIROS, 2009), com a valorização do conhecimento local e ação transdisciplinar (GOMES; GUASP, 2002). Além de representar um exercício pleno da tão falada mas pouco praticada integração pesquisa, ensino, extensão para formação de novas capacidades. A Agroecologia é um enfoque adequado para a promoção de um estilo de agricultura mais respeitoso com a natureza e também para tratar da produção, validação e circulação do conhecimento e para a definição de políticas públicas que tenham preocupação com a construção de uma sociedade sustentável (GOMES; ROSENSTEIN, 2003).

É crescente a consciência sobre a necessidade de entender o meio ambiente e a manutenção da existência em todas as suas formas com maior complexidade, com atenção à qualidade de vida das pessoas no presente e no futuro, sempre com um foco cultural, ambiental e socioeconômico que qualifique a relação Sociedade - Natureza, considerando que a sustentabilidade ecológica é assegurada por diferentes grupos de agricultores familiares mesmo em situação de vulnerabilidade socioeconômica (OLIVEIRA; PAULA, 2016). Torna-se necessário aprofundar a discussão sobre um "mundo sustentável" onde as pessoas possam conviver e incorporar diretamente conceitos como "desenvolvimento sustentável" e "sustentabilidade", os quais são de importância fundamental nas tomadas de decisões em todos os níveis de organização da sociedade (VERONA, 2008).

Nesta perspectiva, e considerando a necessidade de mudanças, a agricultura familiar tem papel fundamental para o processo de construção da sustentabilidade, buscando abrangente e adequada inserção nas políticas públicas e procurando evitar o aprofundamento da crise ambiental no futuro, de forma "que garanta a capacidade dinâmica dos ecossistemas de consertarem seus desvios do equilíbrio mediante processos naturais preservadores da complexa rede de ciclos biogeoquímicos que sustentam a vida no planeta" (CAVALCANTI, 1994). Neste sentido, é necessário entender o que é e o que se pretende com sustentabilidade e operacionalizar todas as múltiplas dimensões deste conceito. Para que o termo sustentabilidade tenha um sentido concreto, torna-se necessário compreender, qualificar, quantificar e apresentar os parâmetros mensurados como contribuição ou caminho de mudança de comportamento, seja de pessoas ou de instituições (GUIMARÃES; FEICHAS, 2009; KEMERICH; RITTER; BORBA, 2014).

O conceito "sustentabilidade" é amplamente utilizado em várias áreas do conhecimento, sempre relacionado com a manutenção dos recursos naturais, a qualidade dos produtos, de vida das famílias dos agricultores e dos consumidores. 
Apesar de conceito complexo e apresentado com diversas nuances dependendo do contexto, indica que o uso produtivo de recursos naturais pode ser orientado para o benefício das populações locais sem prejudicar o meio ambiente (SOUZA; MARTINS; VERONA, 2012). As necessidades de consumo presente devem ser supridas sem restringir as opções futuras, ou seja, os recursos necessários para o futuro não devem ser esgotados para satisfazer o consumo de hoje (WEISS, 1992; GARCEZ, 2014), ficando clara a necessidade de quantificar os processos de desenvolvimento e "quanto" de apropriação dos recursos obedecem a um parâmetro que não coloque em perigo o futuro deste mundo para as futuras gerações.

O presente trabalho apresenta diferentes ações e procedimentos, fundamentados em questões consideradas relevantes sobre sustentabilidade que permeiam o pensamento da sociedade. Objetiva contribuir para a construção de um conhecimento capaz de disponibilizar ferramentas para avaliar a sustentabilidade em agroecossistemas localizados no território sul do Rio Grande do Sul. A este desafio, acrescenta-se a preocupação de construir e utilizar os parâmetros de sustentabilidade identificados em conjunto com as famílias agricultoras articulados com a fundamentação teórica. Destaca-se que no desenvolvimento do processo da avaliação foram amplamente respeitados os atributos da sustentabilidade: equidade, resiliência, adaptabilidade, produtividade e autodependência (VERONA et al., 2007), contemplando as dimensões culturais, ambientais e socioeconômicas.

\section{METODOLOGIA}

Os agroecossistemas que serviram como base de estudo e aplicação da metodologia proposta estão localizados no território sul do Rio Grande do Sul no Rincão do Andrade e Colônia Maciel em Pelotas; na Colônia São Domingos, em Morro Redondo; e no Rincão dos Melões em Canguçu. A ocupação desta região iniciou-se em 1857 com a colonização pomerana em São Lourenço do Sul e atualmente se encontra totalmente desbravada com predomínio dos cultivos de fumo, milho, soja, feijão, frutas (principalmente pêssego) e áreas de pastagens, na sua maior parte, em pequenas propriedades (TEIXEIRA et al., 1986). Característica importante da região é a expressiva presença da agricultura familiar (o município de Canguçu recebe o título de "Capital Nacional da Agricultura Familiar", devido ao grande número de pequenas propriedades rurais) (VIEIRA et al., 2011) e à marcante diversidade étnica e cultural (na região coexistem descendentes de indígenas, imigrantes pomeranos, portugueses, italianos, franceses, quilombolas e da mistura de todas essas etnias) (VIEIRA et al., 2011; GOMES, 2014).

A região apresenta características específicas de desenvolvimento. A Agroecologia assume formas próprias de evolução, marcadas por características locais de organização e de "saber fazer". Durante a década de 80 se iniciam as primeiras experiências com o que hoje se conhece por Agroecologia, até então tratada como "agricultura alternativa" e difundida por meio de organizações ligadas à igreja (Pastoral Rural), de organizações dos agricultores e de ONGs (principalmente o CAPA). A partir dos anos 1990, com a organização dos agricultores em associações e cooperativas (ARPASUL e Sul-Ecológica, entre outras) e com objetivo de qualificar a produção em busca de mercados mais justos, fortalecem-se os modelos de desenvolvimento baseados na Agroecologia. A constituição do Fórum da Agricultura Familiar (meados de 1990), a parceria da Embrapa, das Universidades e da Emater/RS (com a mudança de enfoque a partir dos anos 2000), a conscientização dos consumidores em relação à qualidade dos alimentos auxiliam o processo. Atualmente são mais de 200 agricultores que produzem de forma 
ecológica, dos quais cerca de 50 vendem diretamente nos mercados locais e para as compras institucionais.

Para a realização do trabalho, as unidades foram selecionadas de acordo com o interesse do grupo e a aceitação da família agricultora, com o objetivo de avaliação pontual da sustentabilidade dos agroecossistemas naquele contexto histórico de espaço e tempo. Esse comprometimento, caracterizando o início do trabalho foi denominado "acordo inicial". O método adotado foi a proposta MESMIS Marco de Evaluación de Sistemas de Manejo de Recursos Naturales Incorporando Indicadores de Sustentabilidad (MASERA et al., 1999) executado de forma interdisciplinar e com participação dos atores desde o desenho inicial do projeto, compromissados com a coleta de dados e com a análise dos resultados em conjunto, elaborando as conclusões finais e utilizando as informações geradas, transformando-as em ação (WHYTE; GREENWOOD; LAZES, 1991). Trabalhos recentes confirmam esse método como eficiente na análise dos agroecossistemas e com possibilidade de contribuir na sua gestão (SOUZA; MARTINS; VERONA, 2017).

Durante a realização do trabalho, na aplicação do método MESMIS, foram seguidas as seguintes etapas: 1) estudo detalhado dos agroecossistemas e da proposta de avaliação, identificando os sistemas de manejo, suas características e contexto socioeconômico e ambiental; 2) análise dos pontos críticos: tratando de identificar os fatores limitantes e positivos relacionados com a sustentabilidade; 3 ) seleção de indicadores: nesta etapa foram determinados os critérios de diagnóstico, a partir dos quais derivaram os indicadores estratégicos com os quais foram realizadas as avaliações e construídos indicadores de sustentabilidade; 4) mensuração dos indicadores por meio da formulação de instrumentos de avaliação qualitativos e quantitativos com o objetivo de obter e quantificar as informações; 5) apresentação e integração dos resultados: neste passo foram analisados os resultados apresentados pelos agroecossistemas, através do uso da análise de componentes principais e análise hierárquica de agrupamentos, os quais são testes estatísticos multivariados. Para facilitar a visualização dos resultados foram construídos gráficos tipo radial (ameba). Nesta etapa, ainda foram abordados os principais obstáculos para a sustentabilidade assim como os aspectos que mais a favorecem; 6) indicações gerais para os agroecossistemas: nesta última etapa foi realizada uma síntese da avaliação e propostas alternativas para fortalecer a sustentabilidade dos sistemas de manejo, assim como para melhorar o processo da própria avaliação em trabalhos futuros na região.

Ao realizar essas seis etapas o estudo avançou para um melhor entendimento dos agroecossistemas e dos aspectos que se deseja melhorar, indicando uma série de recomendações que poderão dar início a um redesenho dos agroecossistemas e ao acompanhamento da sustentabilidade destes no futuro. Desta forma gera-se um novo ciclo de estudos, o que permite um monitoramento e acompanhamento constante do agroecossistema. Ao longo deste trabalho, ao executar cada uma das etapas propostas pelo método, foi possível detalhar processos metodológicos específicos para este estudo. Sendo assim, por características do método em uso, conforme foram realizadas as etapas do estudo, foram relatados os resultados iniciais e o caminho metodológico com as especificações necessárias para atingir o objetivo final da avaliação da sustentabilidade dos agroecossistemas.

No desenvolvimento do trabalho foram construídos atributos e indicadores de sustentabilidade para cada agroecossistema em estudo, os quais foram mensurados e monitorados através de entrevistas semiestruturadas, questionários, observações de campo e realizações de transectos, juntamente com as famílias dos agricultores. $\mathrm{O}$ uso desse método, com técnicas qualitativas e quantitativas, permitiu 
a descrição detalhada dos agroecossistemas com seus pontos críticos. A construção de tabelas, diagramas e gráficos facilitou a avaliação desses agroecossistemas de forma integrada, apresentando seus níveis de sustentabilidade na concepção de sustentabilidade construída com as famílias agricultoras e com base nas referências teóricas que fundamentaram o estudo (CASALINHO et al., 2017).

Os resultados encontrados foram entregues aos atores participantes, a família agricultora e os representantes das instituições envolvidas diretamente no trabalho, permitindo a avaliação dos agroecossistemas e a construção de um conhecimento que possa modificar, futuramente, os sistemas utilizados. Ao final do processo foi possível entender e operacionalizar o conceito sustentabilidade, com base num enfoque sistêmico, participativo e interdisciplinar, além de avaliar a sustentabilidade de agroecossistemas com uso de indicadores construídos de acordo com as características específicas de cada um. Cabe destacar o papel da família agricultora como protagonista do trabalho e a ferramenta utilizada como importantes mecanismos de colaboração na gestão e base para a construção de políticas públicas.

\section{RESULTADOS E DISCUSSÃO}

Os relatos da aplicação prática dos conceitos de sustentabilidade, seguindo a proposta do Método MESMIS, são apresentados a partir da sistematização realizada por quatro grupos que visitaram as quatro unidades de produção, sempre tentando compatibilizar a diversidade dentro do grupo e a participação de pelo menos um de seus componentes com conhecimento sobre a região e a família, para facilitar o processo de comunicação. Como o processo foi participativo, cada grupo organizou seu próprio roteiro e forma de realizar o trabalho, razão pela qual os relatos não seguem a mesma ordem ou não contemplam exatamente os mesmos conteúdos, uma característica do próprio processo de pesquisa participativa (GOMES, 2010). Os dados obtidos são apresentados para cada um dos quatro agroecossistemas onde o trabalho empírico foi realizado, identificando-os pela sua denominação regional. A sistematização foi organizada em tópicos, a saber: a) perfil da família e infraestrutura; b) unidade de produção e sistema de manejo; c) recursos naturais: solo, água e preservação ambiental; d) articulação com o mercado, mão de obra e renda; e) organização e participação social e f) atributos e pontos críticos do agroecossistema.

\section{Agroecossistema Rincão do Andrade - Pelotas, RS}

A avaliação do agroecossistema foi realizada por um grupo composto por representantes da Embrapa, do SPAF/UFPel e do CAPA, juntamente com a família de agricultores.

\section{a) Perfil da família e infraestrutura}

A família é composta pelo agricultor, de 64 anos, que cursou até o quinto ano primário completo e pela agricultora, de 56 anos que possui o ensino médio completo e que além de agricultora também atua como agente de saúde. O casal tem um filho que colabora em tempo parcial. $O$ manejo do solo é realizado com o uso de arado, grade e microtrator. Em relação à qualidade de vida, dispõe de boa infraestrutura: energia elétrica, telefone celular, escola, estradas.

\section{b) A unidade de produção e o sistema de manejo}

A unidade de produção familiar apresenta como característica relevo suave ondulado, com terrenos de meia encosta. Os principais itens de produção são pêssego e hortaliças, destacando-se as cucurbitáceas. O sistema de produção é 
realizado com o manejo de plantas espontâneas e leguminosas com o uso de composto orgânico (cama de aviário, esterco ovino e bovino).

c) Os recursos naturais: solo, água e preservação ambiental

A caracterização dos recursos hídricos indicou disponibilidade de água pela existência de cacimba, sanga e açude, muito embora exista divergência entre o casal de agricultores em relação a sua qualidade: "A água está muito boa", segundo o agricultor. "A água está condenada", segundo sua esposa. A propriedade conta com áreas remanescentes de mata nativa, com presença da fauna regional, solo relativamente bem conservado.

d) Articulação com o mercado, mão de obra e renda

A comercialização da produção é realizada principalmente via Mercado Institucional, através da articulação com cooperativa. De forma secundária existe venda de excedentes da produção destinada ao autoconsumo. A mão de obra é constituída pelo casal, o filho e contratação eventual. A necessidade de mão de obra se concentra no período de setembro a janeiro. A renda familiar é composta pela aposentadoria do casal, pela venda da produção (hortaliças, com destaque para cucurbitáceas e frutíferas) para a Cooperativa Sul Ecológica e do pêssego para indústria de conservas. A produção excedente de milho e lenha é vendida ou trocada com vizinhos, indicando a manutenção de práticas solidárias entre vizinhos.

\section{e) Organização e participação social}

A família tem intensa participação nas organizações sociais da localidade: participam da Cooperativa Sul Ecológica e do CAPA há mais de dez anos. A esposa está há cinco anos na presidência da sociedade de cemitérios da colônia francesa. Também participam das atividades da Igreja Luterana. A família tem como atividades de lazer o futebol, jogo de bocha, festas na comunidade e os tradicionais carteados. Em que pese a participação, consideram que ainda existe pouca organização para resolver problemas como a falta de médico no local.

\section{f) Atributos e pontos críticos do agroecossistema Pontos positivos}

Recursos naturais preservados (mata nativa, fauna...), participação na comunidade, assistência técnica, infraestrutura, acesso a mercado institucional e garantia de compra para a produção.

\section{Pontos críticos}

Qualidade da água, escassez de mão de obra, acesso a serviços de saúde, dependência de insumos externos e necessidade de adequação ambiental (licenciamento).

\section{Agroecossistema Colônia São Domingos - Morro Redondo, RS}

O segundo agroecossistema foi visitado e avaliado por um grupo composto por representantes da Emater/RS, Embrapa, UFPel, Bolsistas do CNPq/Embrapa e alunos do SPAF/UFPel em conjunto com a família.

\section{a) Perfil da família e infraestrutura}

A família é composta pelo agricultor, 49 anos e pela agricultora, de 35 anos. Os dois cursaram ensino médio e são naturais do Uruguai. São arrendatários de 27 ha (quinze de área útil, doze de mata nativa) e proprietários de dois hectares. A estrutura da propriedade é composta por casa de alvenaria, galpão e estábulo de madeira, sala de ordenha, ordenhadeira; resfriador de leite, trator e escarificador. O agricultor teve acidente de trabalho e perdeu um pulmão e o movimento de um dos braços, o que não o impede de demonstrar força de vontade, disposição para o trabalho, empolgação e determinação, além de ser empreendedor, tendo como características humildade, simplicidade e espírito coletivo. Em suas palavras: "o bom 
de ser agricultor é a liberdade... sou dono de mim mesmo"; "a pessoa precisa trabalhar mas também tem que viver"; "eu quero ter o conhecimento".

\section{b) A unidade de produção e o sistema de manejo}

Consideram a terra degradada e fraca. No passado observaram que os melhores animais morriam, mas não abandonaram a atividade. Assumiu o aviário do irmão e a produção de morangos. A esposa assumiu a produção leiteira e o agricultor ficou com a parte de campo. Em partes da área usa plantio direto e adubação orgânica, com cama de aviário e esterco bovino. A produção leiteira é obtida de oito vacas com volume diário de 100 litros. Organiza o sistema produtivo pecuário em piquetes e abriga os animais à noite no inverno. Possui dois hectares de silagem, para uso de agosto a novembro, e pastagem de azevém para o inverno e trevo para o verão. Possui milho para silagem, minhocário e nunca gostou de usar veneno. Para subsistência, além do leite, produz carne, ovos, batata e abóbora.

c) Os recursos naturais: solo, água e preservação ambiental

A área apresenta solos rasos e cascalhentos com declividade acentuada e partes degradadas. O capital hídrico é deficiente: o açude tem baixa capacidade de captação e armazenamento e a cacimba apresenta baixa disponibilidade em períodos de seca. $O$ agricultor acredita que a água é de boa qualidade. $O$ agroecossistema apresenta algumas fragilidades principalmente relacionadas a conservação do solo, ainda que apresente boa biodiversidade de espécies nativas e baixa diversidade de espécies cultivadas.

d) Articulação com o mercado, mão de obra e renda

A comercialização do leite é realizada com a COSULATI e diretamente ao consumidor, outros produtos são vendidos para a merenda escolar (PNAE) através da associação. A renda é proveniente principalmente do leite e de auxílio saúde do INSS. Tem acesso a políticas públicas: PRONAF Custeio; PNAE. Consideram a mão de obra existente e disponível suficiente, trocam serviços com vizinhos e realizam serviço em mutirão para silagem, evidenciando a solidariedade entre vizinhos.

\section{e) Organização e participação social}

Quanto à qualidade de vida manifesta satisfação, considera o acesso a saúde adequado, mesmo com segurança alimentar instável. A propriedade dispõe de vias de acesso asfáltico e proximidade da malha urbana. O grau de escolaridade é ensino médio completo. Atuações participativas: Emater/RS, Prefeitura, EMBRAPA e associação de desenvolvimento comunitário dos produtores rurais de Morro Redondo, onde frequenta reuniões mensais para troca de experiências.

\section{f) Atributos e pontos críticos do agroecossistema \\ Pontos positivos}

Otimismo; boa localização da propriedade; vizinhança solidária; desejo de aprender; disposição para o trabalho e bom acesso ao sistema de saúde. Ambições futuras: produzir hortaliças orgânicas e melhorar a condição do solo para poder dobrar a produção leiteira.

\section{Pontos críticos}

Solo degradado; pouca disponibilidade de água; comercialização limitada; necessidade de melhorar o recolhimento e reciclagem de lixo, principalmente o não orgânico; escassa mão de obra e condição física limitada. Demanda aumento da disponibilidade de tecnologias para a produção agroecológica. Possui pouca diversidade de espécies cultivadas e dependência de insumos externos, principalmente para a alimentação animal. 


\section{Agroecossistema Colônia Maciel - Pelotas, RS}

O terceiro agroecossistema foi avaliado por um grupo composto por representantes da Embrapa Clima Temperado e Pecuária Sul, alunos do SPAF/UFPel, Univates e Epagri,/SC, juntamente com a família de agricultores.

\section{a) Perfil da família e infraestrutura}

A família é composta pelo casal de agricultores, ele com 66 anos e ela com 61, uma filha de 43 e um neto de 22 anos com primeiro grau incompleto, o qual trabalha atualmente na construção civil, mas reside na propriedade. Outra filha reside em Joinvile/SC. Residem na propriedade há cerca de quarenta anos, tendo trabalhado por nove anos como meeiros e depois adquirido toda a área. A área total é de 33 hectares e conta com duas residências de alvenaria e três galpões (armazenamento, estábulo). Como equipamentos, possuem microtrator e implementos de tração animal. A família possui, ainda, um veículo Corcel. Inicialmente trabalhavam quase unicamente com a cultura do pêssego, tendo sido um produtor referência nessa cultura. Em 1962 fez um curso de práticas de conservação do solo nos clubes $4 S^{6}$, e começou a estimular os vizinhos nessa prática. Cultivou também milho para pipoca, comercializando em Pelotas. Em função de problemas de saúde, pelo uso de inseticidas, deixou o cultivo do pêssego em princípios da década de oitenta, em uma transição muito rápida, iniciando uma especial trajetória em produção de base ecológica. Naquela época, falava muito em "agricultura alternativa". Participou da Pastoral Rural e de cursos no Centro Ecológico em Ipê e Rincão Gaia. Criou e participou de uma feira de comercialização de produtos agroecológicos em Pelotas, atuando durante dez anos. Hoje comercializa principalmente com a Teia Ecológica e com os moradores da região.

\section{b) A unidade de produção e o sistema de manejo}

As principais culturas vegetais são hortaliças (alho, aipim, cebola, melancia, quiabo, berinjela, cenoura, beterraba, morango, entre outras), fruteiras (banana, goiaba, bergamota, jabuticaba, amoras, videira), flores (rosas), além de milho e amendoim. A criação de animais inclui aves (galinhas), bovinos (para tração e consumo) e peixes. Embora não tenha uma cultura como principal, podem-se identificar algumas com maior importância, como o milho, as rosas, o alho, a cebola e a melancia. Entre as práticas de manejo utilizadas destacam-se preparo do solo com tração animal, uso de sementes próprias, adquiridas e convencionais. A semeadura é manual, e o manejo do solo com adubação verde, adubação orgânica de fonte própria (esterco bovino, húmus de minhoca e compostagem) e adubo químico somente na cultura do milho, quando necessário. Utiliza ainda biofertilizante supermagro, calda bordalesa e sulfocálcica, além de rotação de culturas, capina manual com tração animal, cultivos intercalados, pousio, cobertura morta e irrigação por sulcos. A alimentação animal ocorre em pastagem natural e com milho, realiza controle sanitário animal.

\section{c) Os recursos naturais: solo, água e preservação ambiental}

$\mathrm{Na}$ propriedade existe uma nascente de água que abastece um açude com boa capacidade, formando um curso de água após o açude. A água para consumo é obtida por uma cacimba. A irrigação é feita por gravidade, em sulcos, para algumas culturas a partir da água do açude. O solo apresenta boa qualidade em função do manejo adotado. A família valoriza muito a abundância e a qualidade da água na propriedade, além da topografia, o que facilita o manejo. Existe uma Área de Proteção Permanente e Reserva Legal próxima a 15 hectares. O manejo adotado

\footnotetext{
${ }^{6}$ Clube $4 S$ = Saber, Sentir, Saúde, Servir, estratégia de trabalho da extensão rural com jovens no Brasil entre as décadas 50 e 80 do século passado (SOUZA; OLIVEIRA; COELHO, 2016). Para mais: https://www.youtube.com/watch?v=hJJgiaAZzeA.
} 
permite a existência de grande biodiversidade de espécies nativas e exóticas cultivadas em vários ambientes, como por exemplo orquídeas, frutíferas e arbóreas. A família relata também, com satisfação, a presença de inúmeras espécies da fauna silvestre em sua propriedade, como jacus, jacutingas e tucanos.

\section{d) Articulação com o mercado, mão de obra e renda}

Atualmente comercializa o excedente principalmente com a teia ecológica e com os moradores da região. Grande parte da produção é utilizada para consumo próprio, o que é muito valorizado pela família. Produzem vinho e polpas de morango e amora, o que é considerado um trabalho árduo para o casal, principalmente em função da idade avançada e dos problemas de saúde, embora tenha ficado demonstrada uma grande satisfação e realização para eles. Para a família, a articulação com o mercado deve contar com estratégias de transformação que garantam a qualidade, inclusive do autoabastecimento. A família conta com a renda de duas aposentadorias. $\mathrm{O}$ casal trabalha e toma as decisões em conjunto: a filha que reside na propriedade participa pouco e o neto praticamente não participa dos trabalhos agrícolas, comprometendo a sucessão na propriedade.

\section{e) Organização e participação social}

No passado foi considerado produtor "modelo" de pêssego, utilizando método convencional de cultivo e recebendo muita assistência técnica e apoio da pesquisa. Atualmente não recebe assistência técnica direta, mas sim muitas visitas de pessoas interessadas em conhecer sua propriedade. Participa como palestrante de muitos eventos de Agroecologia. Já foi vinculado a diversos grupos de agricultores, mas deixou de participar, principalmente em função de sua saúde. O agricultor é diácono, tendo relação com muitos vizinhos em função dos eventos religiosos, a festa religiosa da Colônia Maciel é um evento social de grande importância para a região e a família.

\section{f) Atributos e pontos críticos do agroecossistema Pontos fortes}

Preservação de solo e da água, da agrobiodiversidade, baixo uso de insumos externos, conhecimento acumulado em manejo de agroecossistema de base ecológica, segurança alimentar da família.

\section{Pontos críticos}

Baixa disponibilidade de mão de obra, sucessão familiar comprometida, baixa capacidade de geração de renda monetária na propriedade.

\section{Agroecossistema Rincão dos Melões - Canguçu, RS}

O quarto agroecossistema foi avaliado por grupo composto por representantes da Embrapa Clima Temperado, do CAPA e por alunos do SPAF/UFPel, juntamente com os agricultores familiares.

\section{a) Perfil da família e infraestrutura}

A família é composta pelo pai e a mãe (41 anos), um filho de 14 anos, estudante da $8^{\text {a }}$ série, e uma filha de 23 anos casada que não reside na propriedade. $A$ propriedade de 24 hectares foi obtida por herança dos pais do agricultor. Possui doze vacas em lactação e dois terneiros, sendo a ordenha realizada manualmente. Cria patos e galinhas. Como infraestrutura produtiva conta com instalações recentemente renovadas. Foi implantada energia elétrica há dois anos. $O$ sistema de irrigação tem capacidade para operar por duas horas. A propriedade possui residência modesta (chamando atenção o fato de que a família não dispunha de banheiro na residência), galpão, galinheiro, sala do resfriador, implementos e um trator adquirido de "segunda mão": "Este trator é resultado da beterraba!", comenta com orgulho a agricultora.

\section{b) Sistema de produção e manejo}


As principais atividades produtivas realizadas são a produção de leite a pasto, a produção de hortaliças em sistema agroecológico (repolho, beterraba, cebola e abóbora no sistema cultivo em faixas) e um pomar de citrus de 500 plantas com quatorze anos, manejado em sistema convencional com densidade alta, onde ocorre o uso de herbicida, fungicida e adubo sintético sem realização das podas de limpeza e raleio. Falta cobertura de solo, com alta incidência da invasora roseta (Soliva pterosperma). No manejo do gado de leite, a alimentação é realizada em pastagem complementada com milho e ração adquirida na COSULATI. Não dispõe de sala de ordenha, que é realizada manualmente. O manejo das hortaliças é realizado na forma de rotação de culturas (exceto na área da cebola) com uso de adubação orgânica com esterco bovino e de aves não compostados. Compram esterco de aviário via cooperativa; não realizam adubação verde nem culturas intercalares. Usam irrigação por aspersão, por gravidade e com uso de bomba. Para o controle de pragas fazem uso de produtos preventivos, como óleo de neem. Nunca realizou análise de solo. Para autoconsumo produzem milho e batata, além de carne bovina, suína, de frango e ovos.

c) Os recursos naturais: solo, água e preservação ambiental

A propriedade apresenta solo arenoso e com relevo ondulado, com áreas bastante degradadas. A disponibilidade de água é garantida por fontes diversas: açude, poço e cacimba. Possui áreas com floresta nativa, com presença de araucárias, matas ciliares bastante preservadas, áreas de capoeira, bosque de eucalipto e campo nativo. A biodiversidade é considerada relativamente boa. Possui plantas medicinais (malva, capim cidrão, murta, marcela) e também frutíferas (lima, limão bergamota, marmelo-da-índia, banana, uva, ameixa, melancia, limão cravo, laranja, cereja, abacate). "Podendo melhorar!" na expressão do agricultor.

\section{d) Articulação com o mercado, mão de obra e renda}

A produção de leite é comercializada com a COSULATI, que por sua vez é fornecedora de cama de aviário e de insumos para manutenção dos animais, principalmente vacinas. A maior parte das hortaliças é comercializada por meio da Cooperativa Sul Ecológica, quantidades excedentes à demanda da cooperativa são destinadas a atravessadores, o mesmo ocorre com a produção de citrus. A mão de obra é considerada insuficiente, sendo representada pelo casal em tempo integral. $O$ filho atua apenas no gado de leite no período da tarde. Sazonalmente contratam diarista. A família quer permanecer no campo. A renda bruta anual da família foi estimada em cerca de $R \$ 35$ mil, ou cerca de $R \$ 2,9 \mathrm{mil} / \mathrm{mês}$.

\section{e) Organização e participação social}

Dos quatro agroecossistemas considerados no trabalho é o que fica mais distante dos meios urbanos, portanto com mais dificuldade de acesso a mercados e meios de transporte. A linha de ônibus, por exemplo, faz sua "última parada" na porteira da propriedade. Esse relativo "isolamento" é superado pela coleta do leite realizado pela COSULATI e pela articulação com a Cooperativa Sul Ecológica. A família recebe orientações sociais e tecnológicas de técnicos do CAPA.

\section{f) Atributos e pontos críticos do agroecossistema Pontos fortes}

Eficiência no manejo, capacidade de inovação e de aprendizagem, mão de obra suficiente, agrobiodiversidade preservada, demanda por conhecimentos em sistemas de produção de base ecológica, segurança alimentar da família garantida, boa infraestrutura produtiva.

\section{Pontos críticos}

Recursos hídricos: disponibilidade e qualidade química e biológica da água; conservação do solo; falta de saneamento básico (ainda não dispunha de banheiro na residência), infraestrutura habitacional. 


\section{CONSIDERAÇÕES FINAIS}

A análise comparativa evidencia que a aplicação do Método MESMIS na avaliação de sistemas de manejo de recursos naturais em agroecossistemas, incorporando indicadores de sustentabilidade, possibilita tanto aprofundar o conhecimento sobre o modo de funcionamento do agroecossistema como contribui para a qualificação da gestão da unidade de produção familiar, não só no que diz respeito aos recursos naturais como em outras questões complexas relacionadas à sustentabilidade da própria Agricultura Familiar. Neste sentido, pode-se considerar que esta proposta metodológica representa uma poderosa ferramenta de trabalho para agentes do desenvolvimento rural, o que é corroborado em outros estudos (CASALINHO, 2003; SPEELMAN et al.; 2007; VERONA, 2008; THEODORO; CASTRO; ABURAYA, 2011; PASQUALOTTO, 2013; SOUZA, 2013).

Alguns pontos, definidos como críticos pela aplicação do método de trabalho são comuns nas unidades estudadas. Três delas apresentam problemas relacionados a água, seja por quantidade ou pela qualidade. Este é um tema de importância fundamental e transversal a todas as dimensões da sustentabilidade, afetando qualidade de vida, saúde, ambiente e viabilidade do sistema de produção. Não tão crítico ou pelo menos não tão presente nas análises é o solo. Degradação e manejo inadequado foram observados ao mesmo tempo em que o uso de práticas agroecológicas mostram o sucesso dessa estratégia. Estes dois pontos - água e solo - devem merecer especial atenção por parte das agências que desenvolvem programas relacionados com a Agricultura Familiar.

Em se tratando da questão tecnológica dois pontos merecem atenção. O primeiro deles trata dos insumos utilizados, onde em duas das unidades a dependência a insumos externos aparece como ponto crítico, o que também ocorre em relação a falta de conhecimento para produção em sistemas agroecológicos. Em outra unidade, onde o sistema de produção de base ecológica está consolidado, estas questões foram resolvidas, aparecendo como pontos fortes. O que também ocorre no tema agrobiodiversidade, que aparece como ponto forte em três propriedades, sendo considerado ponto fraco em apenas uma delas quanto às reduzidas espécies cultivadas, ainda que a propriedade conte com extensa área de mata nativa. Como indicam Kaufmann et al. (2016) "a conservação e o manejo sustentável dos recursos da agrobiodiversidade continua sendo uma necessidade fundamental para alcançar os objetivos da sustentabilidade e equidade, para garantir que as próprias comunidades desenvolvam uma capacidade de autogestão e para a proteção dos recursos, em seu próprio benefício" como contraponto à "homogeneização dos espaços rurais e de seus produtos".

O tema que merece maior atenção para além das questões tecnológicas sem dúvidas é mão de obra. Seja pela diminuição da capacidade de trabalho, pelo envelhecimento da população do campo ou pelo que pode ser mais dramático: a sucessão comprometida. A permanência dos jovens no campo é uma questão complexa que passa pela ideologia da superioridade do modelo urbano-industrial, pela formação social da família na Agricultura Familiar, pela geração de renda, pelo acesso a novas tecnologias, pela existência de políticas públicas e que não será resolvido por ações isoladas.

Uma constatação importante refere-se ao tema tratado por alguns autores como "capital social", não na vertente econômica de corte neoliberal, como Fukuyama (1999), mas de acordo com Duque (2013), que trata o capital social como um "recurso necessário e imprescindível para a configuração de um desenvolvimento sustentável, na medida em que é capaz de promover a interação 
entre pessoas, estruturas e instituições, sustentadas pela confiança mútua e cooperação, pelo civismo e participação" ou Santos; Carniello; Murade, (2013), cuja abordagem trata da coesão social como estratégia pertinente à promoção do desenvolvimento sustentável e da qualidade de vida. A participação ativa em associações e nas festas comunitárias, a manutenção e mesmo a recriação de práticas solidárias para superar o problema da escassa mão de obra, como a organização de mutirão ou troca de serviços em determinadas épocas ou para realização de algumas práticas, a manutenção de práticas culturais e de lazer, como carteados e jogos de bocha fazem parte de um conjunto de ações coletivas, de valor intangível, em oposição ao individualismo social, motivo pelo qual o capital social deve ser fortalecido ao nível local como forma de promover o desenvolvimento sustentável (DUQUE, 2013).

Outro ponto a considerar é a existência de uma rede local que funciona como ferramenta e importante mecanismo de cooperação e colaboração na gestão das relações institucionais e base para a construção de políticas públicas para a Agricultura Familiar de base ecológica. A participação de representantes de Universidades, da Extensão Rural, da Pesquisa e das organizações dos agricultores familiares de forma coordenada e articulada por meio do Fórum da Agricultura Familiar tem proporcionado o avanço do conhecimento no campo da Agroecologia em suas múltiplas dimensões. Inclusive com a formação de novas competências para atuar no tema. Essa base é que permite a realização de experiências como relatado neste texto.

Finalmente, foram observados pontos fortes de grande relevância, como a questão da garantia da segurança alimentar e o exercício da integração social, o que evidencia o papel da Agricultura Familiar não só como oportunidade de reprodução econômica, mas principalmente como modo de vida, tanto para os agricultores familiares tradicionais como para aqueles que optarem por este desafio. Em meio às contradições e pressões da agricultura moderna e pouco sustentável persistem, emergem e se fortalecem iniciativas e processos sociais que apontam para formas de produção mais sustentáveis baseadas nas cadeias curtas. Estas tendências se mostram crescentes no contexto internacional e nacional, configuram-se como formas diversificadas e viáveis de constituição de sistemas agroalimentares baseados na Agricultura Familiar e na realização da segurança alimentar e nutricional (CONTI; BAZOTTI; RADOMSKY, 2015). O que resta é repassar esta visão para os jovens, rurais ou urbanos, quem sabe criando as condições para a formação de um "novo campesinato"", tal como ocorre em alguns casos na própria região ou até mesmo em outros países.

\section{REFERÊNCIAS}

ALVES, R. C.; ALVES, M. C.; REICHERT, L. J. et al. O Fórum de Agricultura Familiar na Região Sul do RS: Agriculturas de base ecológica - Espaços rurais potenciais para o desenvolvimento do turismo rural sustentável no território. In: CONGRESSO DA SOCIEDADE BRASILEIRA DE SISTEMAS DE PRODUÇÃO, 11. 2016, Pelotas, RS. Anais... Pelotas: Sociedade Brasileira de Sistemas de Produção, 2016. Disponível http://www.sbsp.org.br/z1files/pub/146903201940618_Rosangela-Costa-

em: Alves_Lirio_Forum-AF.pdf. Acesso em 16 set. 2016.

\footnotetext{
${ }^{7}$ Sobre o "novo campesinato" ver a magistral monografia de Monllor (2011).
} 
ALVES, R. C.; REICHERT, L. J. Fórum de agricultura familiar da região Sul do Rio Grande do Sul - o pensar e o agir. In: X CONGRESSO DA SOCIEDADE BRASILEIRA DE SISTEMAS DE PRODUÇÃO. 2014, Foz do Iguaçu, PR. Anais... Foz do Iguaçu: Sociedade Brasileira de Sistemas de Produção, 2014. p. 1288-1294.

ASTIER, M.; PÉREZ-AGIS, E.; ORTIZ, T. et al. Sustentabilidad de sistemas campesinos de maíz después de cinco años: el segundo ciclo de evaluación MESMIS". Leisa: Revista de Agroecología. Ocho estudios de caso. Edición especial, p. 39-46, 2003.

CAPORAL, F. R.; COSTABEBER, J. A.; PAULUS, G. Agroecologia: matriz disciplinar ou novo paradigma para o desenvolvimento rural sustentável In: CAPORAL, F. R.; AZEVEDO, E. O. Princípios e Perspectivas da Agroecologia (Orgs.). Instituto Federal de Educação, Ciência e Tecnologia do Paraná. 2011. p. 45-80.

CASALINHO, H. D.; LIMA, A. C. R.; MARTINS, S. R.et al. Construindo uma reflexão coletiva sobre a noção de sustentabilidade a partir de percepções de agroecologia e agricultura familiar. Agricultura Familiar (UFPA), v. 11, p. 139-156, 2017.

CASALINHO, H. D. Qualidade do solo como indicador de sustentabilidade de agroecossistemas. 2003. 192f. Tese (Doutorado) - Universidade Federal de Pelotas.

CAVALCANTI, C. Breve introdução à economia da sustentabilidade. In: CAVALCANTI, C. (org.) Desenvolvimento e natureza: estudos para uma sociedade sustentável. INPSO/FUNDAJ, Instituto de Pesquisas Sociais, Fundação Joaquim Nabuco, Ministério de Educação, Governo Federal, Recife, Brasil. Octubre 1994. p. 7-13. Disponível em: http://168.96.200.17/ar/libros/brasil/pesqui/cavalcanti.rt. Acesso em: 18 mar. 2015.

CHARÃO-MARQUES, F. Velhos conhecimentos, novos desenvolvimentos: transições no regime sociotécnico da agricultura. A produção de novidades entre agricultores produtores de plantas medicinais no Sul do Brasil. 2009. 220f. Tese (Doutorado). Desenvolvimento Rural, Universidade Federal do Rio Grande do Sul.

CONTI I. L.; BAZOTTI, A.; RADOMSKY, G. F. W. Agricultura familiar e segurança alimentar e nutricional: um estudo sobre a relação produção-consumo nos municípios de Toledo (PR) e contagem (MG). Extensão Rural, Santa Maria, v. 22, n. 1, p. 56-86, jan./mar. $2015 . \quad$ Disponível em: <https://periodicos.ufsm.br/extensaorural/article/view/11935/pdf>. Acesso em: 15 set. 2017.

DUQUE, E. Capital social como instrumento de desenvolvimento sustentável. Configurações [Online], 11, 2013. Disponível em: http://configuracoes.revues.org/1862. Acesso em 16 set. 2016.

FREITAS, A. F.; FREITAS, A. F. Representações sociais como condicionantes dos processos de desenvolvimento territorial. Extensão Rural, Santa Maria, v. 23, n. 1, p. 93-115, jan./mar. 2016. Disponível em: $<$ https://periodicos.ufsm.br/extensaorural/article/view/18130/pdf>. Acesso em: 15 set. 2017. 
FIALHO, M. A. V.; WAQUIL, P. D. O desenvolvimento rural: concepções e referências para a proposição de políticas públicas de desenvolvimento nos territórios rurais. Extensão Rural, Santa Maria, n. 15, p. 129-165, jan./jun, 2008. Disponível em: <http://coralx.ufsm.br/extensaorural/art6ed15.pdf>. Acesso em: 16 set. 2017.

FUKUYAMA, F. Social capital and civil society. The Institute of Public Policy, George Mason University. October 1, 1999 (Prepared for delivery at the IMF Conference on Second Generation Reforms). Disponível em: https://www.imf.org/external/pubs/ft/seminar/1999/reforms/fukuyama.htm.

Acesso em: 16 set. 2016.

GARCEZ, G. S. O princípio da solidariedade intergeracional como pressuposto para a adoção de um paradigma ambiental de sustentabilidade. Interfaces: Revista de Saúde, Meio Ambiente e Sustentabilidade, v. 9, n. 1, p. 109-114, 2014.

GOMES, G. C. As árvores nativas e o saber local como contribuição à sustentabilidade de agroecossistemas familiares na Serra dos Tapes, RS. 2014 352p. Tese (Doutorado em Sistemas de Produção Familiar). Universidade Federal de Pelotas, Pelotas, 2014.

GOMES, J. C. C. As bases epistemológicas da Agroecologia. In: CAPORAL, F. R.; AZEVEDO, E. O. Princípios e Perspectivas da Agroecologia (Orgs.). Instituto Federal de Educação, Ciência e Tecnologia do Paraná. 2011. p. 13-42.

GOMES, J. C. C. As técnicas participativas na pesquisa agrícola: fundamentos teóricos e algumas dificuldades práticas. In: BROSE, M.(org.) Metodologia participativa: uma introdução a 29 instrumentos. 2. ed. Porto Alegre: Tomo Editorial, 2010. p. 307-314.

GOMES, J. C. C.; MEDEIROS, C. A. B. Bases epistemológicas para a ação e a pesquisa em agroecologia: da ciência eficiente à ciência relevante. In: SOUSA, I. S. F.; CABRAL, J. R. F. Ciência como instrumento de inclusão social. Brasília: Embrapa Informação Tecnológica, 2009. p. 249-275.

GOMES, J. C. C.; MEDEIROS, C. A. B.; GOMES, G. C.; REICHERT, L. J. A Estação Experimental Cascata e a construção da base científica da Agroecologia. Agriculturas, v. 3, n. 4, p. 15-19, 2006.

GOMES, J. C. G.; ROSENSTEIN, S. A geração de conhecimento na transição agroambiental: em defesa da pluralidade epistemológica e metodológica na prática científica. Cadernos de Ciência \& Tecnologia, v. 20, n. 3, p. 495-520, 2003.

GOMES, J. C. C.; GUASP, J. T. A interdisciplinaridade como ferramenta para a pesquisa e o desenvolvimento na agricultura familiar. Revista Cientifica Rural, v. 7, n. 1. p. 106-119, 2002.

GUIMARÃES, R. P.; FEICHAS, S. A. Q. Desafios na Construção de Indicadores de Sustentabilidade. Ambiente \& Sociedade, v. XII, n. 2, p. 307-323, 2009.

HANIFAN, L. J. The Rural School Community Centre. Annals of the American Academy of Political and Social Sciences, 67, p. 130-138. 1916. Disponível em: 
http://www.socialcapitalgateway.org/content/paper/hanifan-I-j-1916-

ruralschoolcommunity-centre-annals-american-academy-political-and-s. Acesso em: 16 set. 2016.

KAUFMANN, M. P.; REINIGER, L. R. S.; WIZNIEWSKY, J. G. et al. Resgate e conservação da agrobiodiversidade crioula em lbarama-RS: estratégias de manutenção. Extensão Rural, Santa Maria, v. 23, n. 4, p. 66-78, out./dez. 2016. Disponível em: <https://periodicos.ufsm.br/extensaorural/article/view/21184/pdf>. Acesso em: 16 set. 2017.

KEMERICH, P. D. C.; RITTER, L. G.; BORBA, W. F. Indicadores de sustentabilidade ambiental: métodos e aplicações. Revista Monografias Ambientais: REMOA, $v$. 13, n. 5, p. 3723-3736, 2014: Edição Especial LPMA/UFSM.

MASERA, O.; ASTIER, M.; LÓPEZ-RIDAURA, S. Sustentabilidad y manejo de recursos naturales: el marco de evaluación MESMIS. México: Mundi-Prensa, 1999. $109 p$.

MASERA, O.; LÓPEZ-RIDAURA, S. Sustentabilidad y sistemas campesinos. México: GIRA - Grupo Interdisciplinario de Tecnologia Rural Apropriada /Mundi Prensa. 2000. 346p.

MONLLOR, N. Explorant la jove pagesia: camins, pràctiques i actituds en el marc d'un nou paradigma agrosocial. 2011. 440f. Tese (Doutorado) - Universitat de Girona.

NICOLA, M. P.; CHARÃO- MARQUES, F. Transições em direção ao uso sustentável e conservação dos campos sulinos gaúchos: o lugar da pecuária familiar. Extensão Rural, Santa Maria v. 23, n. 1, p. 58-77, jan./mar. 2016. Disponível em: <https://periodicos.ufsm.br/extensaorural/article/view/17772/pdf>. Acesso em: 15 set. 2017.

OLIVEIRA, L. C.; PAULA, H. M. M. Ecologismo dos pobres: possibilidades de leituras contra-hegemônicas frente ao modelo hegemônico do agronegócio. In: OLIVEIRA, M. M.; FOLGADO, C. A. R. Agrotóxicos: violações socioambientais e direitos humanos no Brasil. Anápolis: Editora Universidade Estadual de Goiás, 2016. p. 83-97.

PASQUALOTTO, N. Avaliação de sustentabilidade em agroecossistemas hortícolas, com base de produção na Agroecologia e na agricultura familiar, na microrregião de Pato Branco - PR. 2013. 125f. Dissertação (Mestrado) - Programa de Pós-Graduação em Desenvolvimento Regional, Universidade Tecnológica Federal do Paraná.

PERERA, A. F.; GOMES, J. C. C. O uso de metodologias participativas na democratização do conhecimento: avaliação de rede de referência na Região Sul do RS. Extensão Rural, Santa Maria, v. 16, n. 18, p. 123-146, jul./dez. 2009. Disponível em: <http://w3.ufsm.br/extensaorural/art5ed18.pdf>. Acesso em: 15 set. 2016.

RECH, C. M. Entre mediações e (re) configurações: a trajetória do Fórum de Agricultura Familiar. Interseções, Rio de Janeiro, v. 17, n. 1, p. 274-293, 2015. 
Doi: $10.12957 /$ irei.2015.18046

REICHERT, L. J.; GOMES, J. C. C. Pesquisa participativa em rede de referência. Revista Brasileira de Agroecologia, v. 1, n. 1, 2006.

RIBEIRO, F. P.; CALLOU. A. B. F. Capital social de pescadores e a criação da reserva extrativista de Rio Formoso - Pernambuco. Extensão Rural, Santa Maria, v. 22, n. 4, p. 24-42, out./dez. 2015. Disponível em: <https://periodicos.ufsm.br/extensaorural/article/view/10903/pdf>. Acesso em: 16 set. 2017.

SANTOS, M. J.; CARNIELLO, M. F.; MURADE, J. F. G. Relações entre cultura popular, capital social e desenvolvimento sustentável no município de São Luiz do Paraitinga -SP-Brasil. REDES - Revista Desenvolvimento Regional, Santa Cruz do Sul, v. 18, n. 1, p. 8-20, 2013.

SEVILLA GUZMÁN, E.; GONZÁLEZ DE MOLINA, M. (eds.). Ecología, campesinado e historia. Madrid: La Piqueta, 1993.

SOPEÑA, M. S. Papel do estado brasileiro na perspectiva do desenvolvimento produtivo: correspondências e interfaces com a literatura internacional sobre extensão rural. Extensão Rural, Santa Maria, v. 22, n. 3, p. 110-127, jul./set. 2015. Disponível em: <https://periodicos.ufsm.br/extensaorural/article/view/16436/pdf>. $\begin{array}{llll}\text { Acesso } & \text { em: } & 15 & \text { set. }\end{array}$

SOUZA, R. T. M. Gestão ambiental de agroecossistemas familiares mediante o método MESMIS de avaliação de sustentabilidade. 2013. 216f. Dissertação (Mestrado) - Programa de Pós-Graduação em Engenharia Ambiental, Universidade Federal de Santa Catarina.

SOUZA, R. T. M.; MARTINS, S. R.; VERONA, L. A. F. A metodologia MESMIS como instrumento de gestão ambiental em agroecossistemas no contexto da Rede CONSAGRO. Agricultura Familiar (UFPA), v. 11, p. 39-56, 2017.

SOUZA, R. T. M.; MARTINS, S. R.; VERONA, L. A. F. Gestão ambiental de agroecossistemas familiares mediante utilização do método MESMIS. In: XI CONGRESSO DA SOCIEDADE BRASILEIRA DE SISTEMAS DE PRODUÇÃO. 2012, Luziania, GO. Anais... Luziania: Sociedade Brasileira de Sistemas de Produção, 2012. 21p.

SOUZA, S. B.; OLIVEIRA, M. L. R.; COELHO, F. M. G. A atuação dos clubes 4S em Minas Gerais e a ideia de juventude rural na Emater/MG. Holos, Ano 32, v. 1, p. 142-152, 2016.

SPEELMAN, E. N.; LOPEZ-RIADURA, S.; COLOMER, N. A. et al. Ten years of sustainability evaluation using the MESMIS framework: Lessons learned from its application in 28 Latin American case studies. International Journal of Sustainable Development and World Ecology, v. 14, n. 4, p. 345-361, 2007. Disponível em: http://dx.doi.org/10.1080/13504500709469735. Acesso em: 16 maio 2014.

TEIXEIRA, M. B., COURA NETO, A. B.; PASTORE, U. et al. Vegetação. As regiões fitoecológicas, sua natureza e seus recursos econômicos. Estudo fitogeográfico. In: 
Levantamento de recursos naturais. Instituto Brasileiro de Geografia e Estatística. Rio de Janeiro: IBGE, v. 33, p. 541-632, 1986.

THEODORO, V. C. A.; CASTRO, F. P.; ABURAYA, F. H. Indicadores ecológicos de sustentabilidade de unidades de produção agrícola do assentamento Facão Cáceres, MT, Brasil. Revista Brasileira de Agroecologia, v. 6, n. 3, p. 21-33, 2011.

VERONA, L. A. F. Avaliação de sustentabilidade em agroecossistemas de base familiar e em transição agroecológica na região sul do Rio Grande do Sul. 2008. 192f. Tese (Doutorado) - Programa de Pós-Graduação em Agronomia, Universidade Federal de Pelotas.

VERONA, L. A. F.; CASALINHO, H. D.; MASERA, O. et al. Uso de indicadores compostos na análise de sustentabilidade de agroecossistemas de base familiar na região Sul do Rio Grande do Sul. Cadernos de Agroecologia, v. 2, n. 2, p. 491-494, $2007 . \quad$ Disponível em: http://www.abaagroecologia.org.br/revistas/index.php/cad/article/view/2822/2429. Acesso em: 16 set. 2016.

VIEIRA, V.; QUOOS, J. H.; VERDUM.; R. Compartimentos morfo-pedogênicos: potencialidades e limites na sustentação dos sistemas de cultivo e criação no município de Canguçu, RS-Brasil. Para Onde!? v. 5, n. 1, 2011.

WEISS, E. B. Intergenerational equity: a legal framework for global environmental change. In: WEISS, E. B. (ed.) Environmental change and international law: new challenges and dimensions. Tokyo: United Nations University Press, 1992. Disponível em: http://archive.unu.edu/unupress/unupbooks/uu25ee/uu25ee00.htm. Acesso em: 16 set. 2017.

WHYTE, W. F.; GREENWOOD, D. J.; LAZES, P. Participatory action research: through practice to science in social research, In: WILLIAM F. W. (ed.) Participatory action research. Newbury Park: Sage Publications. 1991. Disponível em: http://dx.doi.org/10.4135/9781412985383.n2. Acesso em: 16 out. 2015. 